\title{
9. COVID-19 is shifting consumption and disrupting dairy value chains in Ethiopia
}

\author{
Agajie Tesfaye, Yetimwork Habte, and Bart Minten
}

The COVID-19 crisis is having a range of impacts on food consumption and value chains everywhere containment measures, lost incomes, and perceptions of disease risk are altering food availability and consumer preferences. To understand the effects of the COVID-19 crisis on Ethiopia's important dairy sector, we conducted a qualitative appraisal of the dairy value chain supplying Addis Ababa. Between April 15 and May 10, we interviewed nearly 100 commercial and small dairy farmers in urban and rural areas, dairy processors, traders, development agents, urban retailers, and consumers.

Overall, the survey indicates that the Ethiopian dairy sector has experienced only moderate impacts especially compared to the livestock sectors in China and other countries. However, certain segments of the industry - particularly raw milk vendors and small dairy shops - have been hit hard.

\section{Downstream: Urban retail and consumption}

Data from two recent large-scale household surveys indicate that the consumption of dairy products in Addis Ababa has decreased since the start of the COVID-19 crisis. In January/February 2020, 56\% of residents questioned said that they consumed dairy products in the previous seven days. In May, this number declined to $45 \%$ of interviewed households (Figure 1). All income groups decreased their consumption, except for the richest quintile, where the share of consuming households changed little.

An important reason for falling consumption is the fear of disease risk. More than half of respondents in the household survey said they were avoiding the consumption of animal-sourced foods (meat, milk, yogurt, cheese) due to the perceived COVID-19 risk. This widespread perception is apparently linked to Ethiopian media reports at the beginning of the outbreak suggesting that consumption of fish and animal-sourced products was associated with greater chances of infection. However, COVID-19 transmission via food is not considered a significant problem, and the risk from dairy products in particular is minimal; the virus typically spreads through close person-to-person contact via airborne respiratory droplets.

While media outlets later corrected these warnings regarding dairy products, the Ministry of Health has warned the public to avoid consumption of raw foods because of the potential risk of contamination through droplets coming from food handlers. Thus the perception of risk from dairy products remains - particularly from raw milk. Our interviews indicate a significant drop in the demand for raw milk; a steady, or even higher, consumption of pasteurized milk; and an increase in purchases of powdered milk, as the latter two are considered safer by consumers. 
FIGURE 1 Dairy consumption in Addis Ababa, Jan./Feb. and May 2020

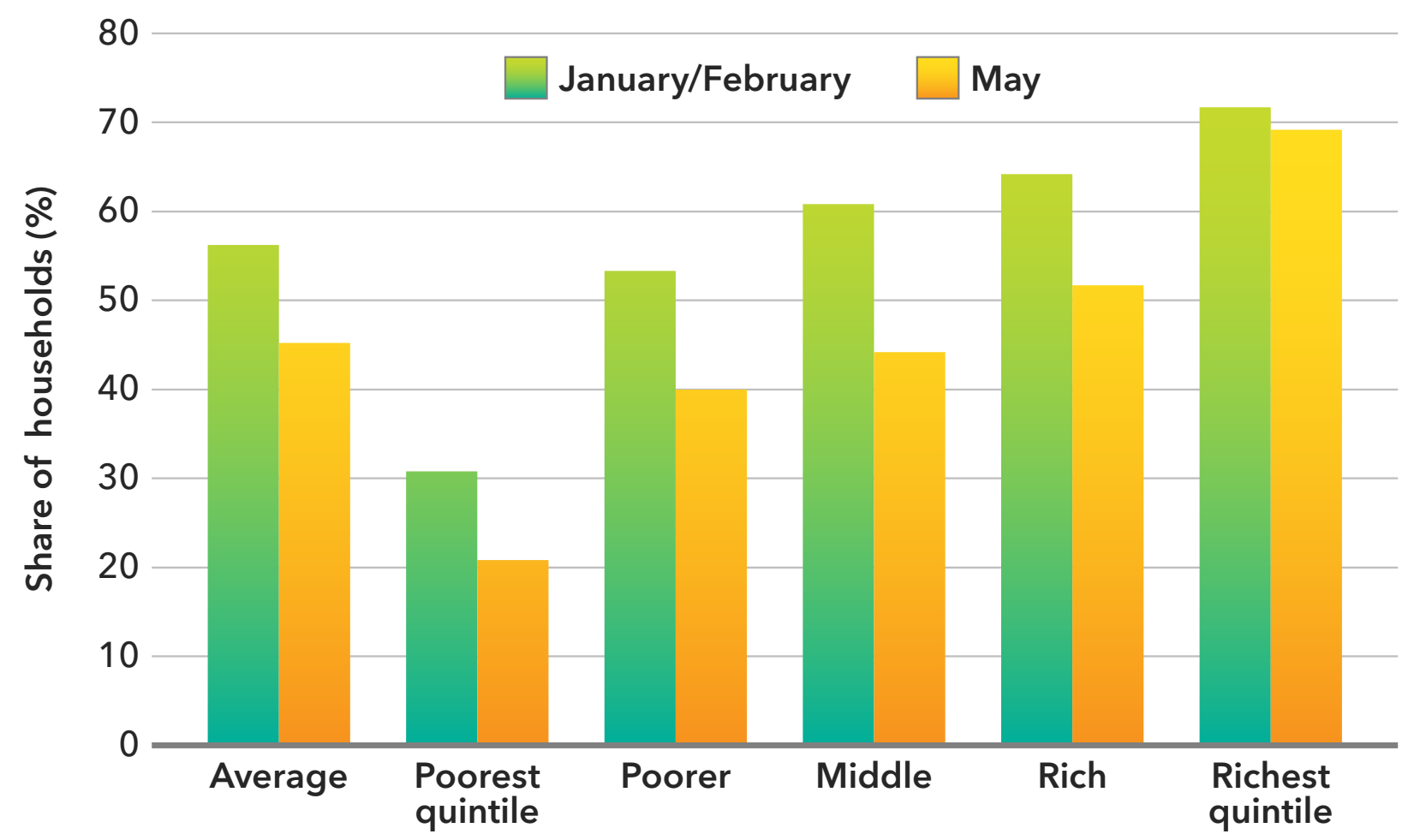

Source: Wolle et al. (2020); Hirvonen et al. (2020).

Addis Ababa's dairy shops - where people can buy milk and yogurt, and there is also often space to sit and eat - are estimated to distribute $11 \%$ of the city's liquid milk, much of it in raw form, and more than $25 \%$ of its yogurt. Dairy shop owners or managers we interviewed all complained of a sharp reduction in customers, largely because consumers link raw milk, or yogurt made from raw milk, with an increased risk of contracting the virus.

Social distancing measures are also impacting business. Dairy shops are often located in areas that are now much less busy - such as near universities, whose students have gone home. Most are also small and cannot easily accommodate orders to keep customers widely separated. Such distancing measures are also leading to a drop in demand for milk products by coffeehouses and pastry shops, we find, another important outlet for dairy.

We also see a decrease in activities by small informal distributors of raw milk. Supplied by urban dairy farms and also in part by small-scale milk collectors, they sell their product to urban residents in plastic jerrycans of 10 to 20 liters. They often also use public transport. The consumer-clients whom we talked to indicated that they were scared of buying from such vendors due to perceived COVID-19 risks. The reasons mentioned included the high number of visits such traders make to different houses, their lack of health precautions, and the fear of contamination of utensils used by collectors, milkmen, or vendors across this raw milk marketing chain. 
Interviews with owners of regular grocery shops - which are very important for the distribution of dairy products in Addis - and of supermarkets indicate that demand was down, as usual, during the fasting period in March and April, and that it has since returned to normal levels, or that it was even up compared to the same period in other years. Some indicated that they were running out of supplies. But dairy demand has shifted: They all indicated that the demand for powdered milk, which normally makes up almost $10 \%$ of the dairy expenditures of urban households in Addis, significantly increased. They suggested that consumers believe that the processed product is less risky than raw milk and is also appealing because it can be stored indefinitely - important given the uncertainty surrounding stay-at-home measures, the risk associated with going out, and the fear that food supply chains might break down.

\section{Midstream and upstream: Dairy processing companies, collectors, and farmers}

These changes in consumer preferences pass down through the dairy value chain - in particular, distributors, collectors, and rural farmers involved in the raw milk value chain have been severely affected by the COVID-19 crisis. Farmers are less able to sell their milk. As a result, more milk was processed and the butter supply rose, and butter prices fell sharply in rural areas. Some dairy households reported incidences of wasted milk as they could not find buyers, and some indicated they were increasing their own dairy consumption.

Meanwhile, prices of liquid milk remained stable in urban retail markets and prices for producers supplying dairy processing plants did not change. Marketing margins did not change very much either. On the cost side, feed prices increased $30 \%$ to $40 \%$ over several months, before dropping back to normal levels. Wheat bran and oil-cake were the most affected. The spikes may have been due to wheat factories receiving less supply from rural areas and/or reducing operations by placing some workers on leave in response to COVID-19. Transportation problems may also have contributed. But overall, all farmers interviewed said production has not fallen since the start of the COVID-19 crisis.

We also assessed access to veterinary medicines. These seem to be less available in public pharmacies but can still be found in private ones. However, stakeholders in rural production areas indicated that prices had gone up by $15 \%$ to $20 \%$ since the start of the COVID-19 crisis. Retail prices often increased because prices from distributors had increased, as their international supply channels might have been disrupted.

\section{Conclusion}

Overall, despite the exceptions, the Ethiopian dairy sector has proven surprisingly resilient in the face of the pandemic, control measures, and consumer worries about food contamination. This might be explained by the fact that the Ethiopian production system is much less dependent on marketed inputs than that of some other countries. Nevertheless, our survey indicates a number of problems remain, including the challenge of accurately communicating the COVID-19 disease risks associated with food to consumers. It is also important to further monitor these developments. A new household survey that will be fielded in the coming weeks in Addis Ababa might provide new needed insights. 
We thank Anne Bossuyt (IFPRI), Fantu Bachewe (IFPRI), Kaleab Baye (Addis Ababa University), and Rinus van Klinken (SNV) for comments on an earlier version of this post.

This work was funded in whole or part by the United States Agency for International Development (USAID) Bureau for Food Security under Agreement \# AID-OAA-L-15-00003 as part of the Feed the Future Innovation Lab for Livestock Systems, implemented by the Institute of Food and Agricultural Sciences of the University of Florida in partnership with the International Livestock Research Institute (ILRI).

Originally published June 1, 2020. 